\title{
Clinical supervision in Anaesthesiology - can evaluation make it more effective?
}

\author{
A Abayadeera ${ }^{1^{*}}$, V Pinto $^{2}$ \\ Professor of Anaesthesiology, Faculty of Medicine, University of Colombo, Sri Lanka, Professor in \\ Anaesthesiology, Faculty of Medicine, University of Peradeniya, Sri Lanka.
}

Effective clinical and educational supervision is mandatory for postgraduate education. However, it is not easy to define and evaluate effective supervision, capability, the outcomes of supervision and how it affects the trainee, patient care and the service.

\section{Postgraduate training in Sri Lanka}

In Sri Lanka, a postgraduate trainee in anaesthesiology is a post registration MBBS medical officer who has had a minimum of 6 months initial training and has completed the selection examinations in clinical anaesthesia and basic sciences. Then they progress through a rigorous specified rotational training programme as a registrar and a senior registrar till they are board certified as specialists. While the quantitative aspect of such training is easily determined by the number of hours utilized, evaluation of the qualitative aspect is not easy. This progression involves different educational processes. Acquisition of knowledge, skills and attitudes required for this progression will come from his/her self-study, organized educational programs, and most importantly the 'hands on' training received from the clinical supervisors. It is an ongoing process changing gradually from intense supervisor directed hands on coaching in the early stages, to the supervisor standing back and encouraging more independent decision making and technical procedures as the trainee progresses. The goal is progressively increasing confidence and independence, while decreasing intensity of supervision, without jeopardizing patient safety.

*Correspondence: A Abayadeera

Email: anujaa@sltnet.lk

iD https://orcid.org/0000-0003-0073-5587

DOI: http://doi.org/10.4038/slja.v26i1.8300

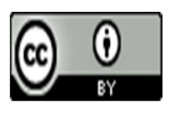

Who is a supervisor?

A supervisor is a person who provides guidance and feedback on matters of personal, professional and educational development in the context of a trainee's experience of providing safe and appropriate patient care. ${ }^{1}$

What makes an effective clinical supervisor?

An effective clinical supervisor must have many attributes; some inbuilt and some acquired with training. These attributes should ensure safety of the trainee and patient in the course of clinical care, provide initial training and plan continuing education, ensure an appropriate number and level of clinical duties, give feedback on performance informally and through appraisals, monitor progress and provide career advice. ${ }^{2}$ Supervision requires direct observation, continual appraisal and feedback and sharing of knowledge and clinical judgment.

Traditionally anaesthesia training has been by apprenticeship ("at the feet of the guru!"), very much supervisor directed with modelling (show how), coaching (intense training), and scaffolding (challenging the trainee with tasks). Today there is a paradigm shift towards more and more selfdirected learning with emphasis on reflection (recognizing their individual strengths and weaknesses), articulation (reasoning) and exploration (formulating their own goals).

Ensuring patient and trainee safety is always a priority. In this context, it is important that the clinical supervisor is able to assess the level of competence of the trainee in order to perform without compromising patient safety. To enable the trainee to learn new skills the clinical supervisor needs to plan adequate induction to the training placements, and keep trainees informed of opportunities available to reduce stress and improvement of communication skills. Instructions should be given regarding safety procedures when 
handling equipment that can cause harm to the trainee, for the prevention and control of transmissible diseases, fire and other emergencies, personal safety and ensure reasonable out of hours working commitments.

\section{Trainer-trainee contract}

Undoubtedly, training is a partnership between a trainer (supervisor) and trainee and both have responsibilities and obligations in this contract.

The trainees should familiarize themselves with the overall objectives of the training programme, the prospectus and study guide, and the outcomes expected at each stage. A trainee should keep records of their experiences and achievements so that discussions about future training is possible. Increasingly most programmes expect the trainees to maintain a portfolio which is used as an assessment tool. It is best that each trainee takes responsibility for their own training by planning the supervised sessions beforehand. They also should develop self-awareness and reflective practice in order to fulfil their training needs.

What are the obligations of the trainer/supervisor? They need to provide well organized and comprehensive training and ensure their trainees achieve the objectives set out. They should be accessible, provide a safe and supportive environment for training, observe closely their trainees in practice and most importantly provide honest, fair and constructive feedback at regular intervals.

In order to achieve a good trainee supervisor contract, it is best that the supervisor arranges an early meeting during the placement to get to know each other and understand the goals, aspirations and expectations before agreeing on the plan of training and laying down the ground rules. This meeting should review progress so far, the specific objectives for this placement and also identify the methodology to achieve the objectives and the goals. The final meeting at the end of this term should be an appraisal of progress made and what more is required at the next placement.

Training the clinical supervisor

Training clinical supervisors is an institutional responsibility. The Postgraduate Institute of currently conducts examination training workshops and is planning a more intensive course designed to train the trainers. This will provide the opportunity for the supervisors to obtain knowledge and expertise in training methodology, clinical supervision and appraisal.

What skills should a supervisor harness to be effective? There are many and include formal skills in teaching and facilitating learning, identification of alternatives and problem solving and motivational skills. They need to acquire appraisal skills to observe and reflect and provide constructive feedback on performance. They should be knowledgeable and open to discussion providing a supportive environment, fostering self - confidence and autonomy in the trainee. They need to show reliable service management skills, be excellent role models, show safe clinical practice, leadership, team work and open communication and have the ability to critically self-evaluate. They have to be the advocate and the negotiator for the trainee and possess efficient time management and organizational skills. Of vital importance is the ability to recognize the specific individual needs and personality of the trainee and provide a nonthreatening, non-intimidating environment for the trainee to develop at his/her own pace.

The way forward

In the future, Postgraduate Institute of Medicine, Sri Lanka, is planning to implement "feedback on trainers/supervisors" by the trainees. In the UK, some Schools of Anaesthesia have moved further with feedback from trainees through anonymized questionnaires and online for a to encourage trainees to discuss and share experiences at "trainees only" meetings. ${ }^{3}$

Oliviero Filho 4 has designed a 9-item supervisor scoring system - a questionnaire to trainees on anaesthesia care planning, availability, presence during critical events, patient safety, patient based learning, effective feedback, encouraging trainee autonomy, professionalism, and inter-personal skills. This has been validated in many centres by simple e-mail questionnaires sent out to all trainees and should be the way forward for us too.

The next step could be the addition of external validation by direct observation and assessment of trainer-trainee interaction in the operating room by 
a qualified and experienced third party. It is vital that all parties concerned should not feel intimidated, but recognize the importance of such evaluation to the advancement of our specialty and overall patient care.

\section{References}

1. Kilminster SM, Cottrell D, Jolly BC, Grant J et al. AMEE Guide No. 27: Effective educational and clinical supervision. Medical Teacher. 2007; 29:219

https://doi.org/10.1080/01421590701210907 PMid:17538823

2. Kilminster SM, Jolly BC. Effective supervision in clinical practice settings: a literature review. Medical Education 2000; 34: 827-840. https://doi.org/10.1046/j.1365-2923.2000.00758.x

3. Ward, P. Feedback for trainers in trouble. Anaesthesia. 2014; 69 (2); 185-186 https://doi.org/10.1111/anae.12575 PMid:24443862

4. De Oliverio Filho GR, Dal Mago AJ, Garcia JHS, Goldschmidt R. An instrument designed for faculty supervision evaluation by anaesthesia residents and its psychometric properties. Anaesthesia Analgesia 2008; 107(4);1316-1322

https://doi.org/10.1213/ane.0b013e318182fbdd

PMid:18806047 